\title{
Projeto de um banco de ensaio de desgaste do tipo "pin-on-disc"
}

\section{(Design and construction of a pin-on-disc bench for wear testing)}

\author{
D. T. L. Ramos ${ }^{1}$ E. M. J. A. Pallone ${ }^{2}$, B. M. Purquerio', C. A. Fortulan \\ ${ }^{1}$ Departamento de Engenharia Mecânica, Escola de Engenharia de S. Carlos, Universidade de S. Paulo, Av. \\ Trabalhador São-Carlense 400, S. Carlos, SP 13566-590 \\ ${ }_{2}^{2}$ Departamento de Engenharia de Biossistemas, FZEA, Universidade de S. Paulo, Av. Duque de Caxias Norte \\ 225, Pirassununga, SP 13635-900 \\ danillotlramos@hotmail.com, eliria@usp.br,purqerio@sc.usp.br,cfortula@sc.usp.br
}

\begin{abstract}
Resumo
O estudo trata do projeto, fabricação e validação de um banco de ensaio de desgaste do tipo pin-on-disc. Estudos de atrito e desgaste de deslizamento de cerâmicas geralmente tem utilizado equipamentos do tipo pin-on-disc. Este tipo de equipamento tem sido referenciado como um dos que melhor representa o estudo de desgaste e que apresenta melhor reprodutibilidade dos resultados em diversos laboratórios. O presente trabalho, no cumprimento da normalização vigente e no atendimento de interesses dos diversos usuários, pesquisadores ou técnicos, objetiva o projeto e a fabricação de banco de ensaio de desgaste do tipo pin-on-disc para ensaio de amostras com variadas dimensões obtidas por diversas técnicas de manufatura. As premissas do projeto visam um equipamento que garanta a manutenção do torque e velocidade de deslizamento ao longo do experimento, calibragem da carga no próprio equipamento, medição de coeficiente de atrito ao longo do ensaio, possibilidade de ensaio à seco ou com fluídos e amortecimento das vibrações. Um protótipo compacto foi construído e validado no desgaste do par tribológico de alumina. Foi obtido um equipamento de fabricação accessível e reprodutível baseado em acionamento por servo motor, mesa de granito sintético, suspensão por coxins para amortecimento das vibrações e contínua medição de força de atrito durante o experimento. Para analise de validação foi aplicada carga de $30 \mathrm{~N}$ e velocidade de deslizamento de $0,5 \mathrm{~m} / \mathrm{s}$ obtendo taxa de desgaste média de $15 \times 10^{-6} \mathrm{~mm}^{3} / \mathrm{N}$.m e volume de desgaste de $1,2 \mathrm{~mm}^{3}$ após $4000 \mathrm{~m}$ de deslizamento gerando força de atrito média de $23 \mathrm{~N}$, resultados estes compatíveis com ensaios similares. Palavras-chave: projeto mecânico, desgaste, desgaste de cerâmica, pin-on-disc.
\end{abstract}

\begin{abstract}
This study presents the design, manufacture and validation of pin-on-disc bench for wear. For studies of sliding friction and wear of ceramics is generally applied pin-on-disc apparatus. This type of equipment has been referred the best one is the study of wear and shows better reproducibility of results in different laboratories. This work, in compliance with current standards and care of interests of different users, researchers and technicians, objective the design and manufacturing of a pin-on-disc bench for testing of samples with varied dimensions and obtained by different manufacturing techniques. The entrances of project providing for the maintenance of the sliding velocity and torque during the experiment, calibration of load on the equipment, measuring coefficient of friction during running, possibility of wet or dry test and damping vibrations. A compact prototype was built and validated with wear of tribologic alumina samples pair. Affordable and reproducible equipment was obtained based on: driven by servo motor, synthetic granite table and suspension pads for vibration dampening and continuous measurement of frictional force during the experiment. For the validation was applied alumina tribologic pair, load at $30 \mathrm{~N}$, and sliding velocity at $0.5 \mathrm{~m} / \mathrm{s}$. The maim results was wear rate as $15 \times 10^{-6} \mathrm{~mm}^{3} / \mathrm{N} . \mathrm{m}$ and wear volume as $1.2 \mathrm{~mm}^{3}$ after $4000 \mathrm{~m}$ of sliding, the friction force was an average $23 \mathrm{~N}$, these results are consistent with similar studies.
\end{abstract}

Keywords: design, wear, ceramic wear, pin-on-disc.

\section{INTRODUÇÃO}

O desgaste é um dos três problemas industriais mais freqüentes que conduz a substituição de componentes e ou manutenção de equipamentos, os outros dois são a fadiga e a corrosão. O desgaste é raramente catastrófico, mas reduz a eficiência de operação através do aumento da perda de potência, consumo de lubrificantes e substituição de componentes. Há vários mecanismos de desgaste ocorrendo simultaneamente em um par em contato deslizante: desgaste abrasivo; desgaste adesivo; desgaste corrosivo; desgaste devido ao fluxo; devido à fadiga e devido à fusão e difusão. Atrito e desgaste não são propriedades intrínsecas do material, mas sim características do sistema de aplicação. As análises das condições que causam o desgaste e dos muitos mecanismos que contribuem para a causa de danos sinalizam para a solução de um problema particular que depende, sobretudo, da identificação precisa da natureza das variáveis envolvidas.

O mecanismo de desgaste pode ser observado em 
três regimes distintos de severidade de contato, ou seja, o regime de desgaste brando (I), o regime de transição de desgaste brando para desgaste severo (II) e o regime de desgaste severo (III) [1]. No regime de desgaste brando (I) as superfícies são pouco afetadas pelo desgaste, ocorre um desgaste microabrasivo nos cantos dos poros; nos defeitos superficiais e nos finos riscos superficiais que podem ser responsáveis pela nucleação de trincas e iniciação do desgaste [2]. O regime de transição (II) ocorre quando o nível de tensão dinâmica na superfície excede o limite crítico para iniciação da propagação incontrolável das trincas, com resultado da ruptura da superfície. Os mecanismos de deterioração dominantes são deformação plástica e fratura da superfície. Já no regime severo de desgaste (III) a superfície é coberta pelos debris desgastados. Debris consistem em finos fragmentos moídos que localmente são compactados termo-mecanicamente para formar camadas de tribo debris que controlam o desgaste e a resposta ao atrito.

$\mathrm{O}$ desgaste abrasivo tem sido definido como o deslocamento de material causado por partículas ou protuberâncias de elevada dureza [3, 4]. Quando uma ou mais partículas duras, sujeitas à aplicação de força normal contra uma superfície são deslizadas (atrito) é gerado um sulco ou uma escavação tendo o desgaste abrasivo dos dois corpos. Por outro lado, quando partículas duras são aprisionadas entre duas superfícies que deslizam entre si, pode ocorrer o chamado desgaste abrasivo de três corpos. Dentro da estrutura desta definição geral, uma variedade de diferentes processos pode estar envolvida na produção de danos superficiais e fragmentos $[4,5]$.

A taxa de desgaste abrasivo e os mecanismos de desgaste podem ser influenciados por vários fatores como: material (tamanho do grão, módulo de elasticidade, condutividade térmica, dureza); ensaio (forma, carregamento, tipo de movimento, aspereza, vibração, número de ciclos); meio ambiente (temperatura, contaminação, umidade, atmosfera) e lubrificação (tipo de lubrificante, estabilidade de lubrificante, tipo de fluido) $[3,6]$.

\section{Desgaste em cerâmica}

Podem ser identificadas diferenças no estudo de desgaste entre os metais (deformação) e as cerâmicas (fratura). A mais importante está relacionada com configuração de contato. Para os metais normalmente emprega-se seções planas de contato onde é aplicada pressão constante de contato. Já para as cerâmicas utiliza-se uma configuração de contato não planas como: ball-on-flat, ball-on-ball, ou cylinder-on-flat, onde é fixada uma determinada carga e ocorre mudanças de pressão de contato nominais (mais justamente diminuições) com o deslizamento e desgaste do corpo em contato ocorre um aumento na área de contato. [7]

Devido a fragilidade das cerâmicas, vários tipos de trincas são introduzidos pelo atrito ao redor da zona de contato, como trincas hertzianas, laterais, medianas e radiais. Estas trincas são mostradas esquematicamente na Fig. 1a. Dependendo do valor da pressão de contato no

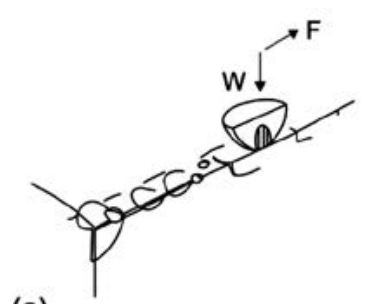

(a)

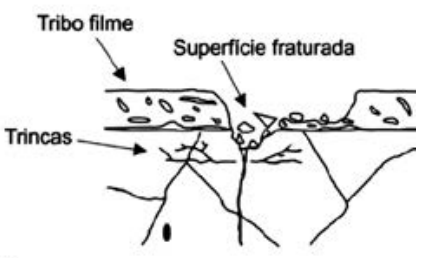

(b)

Figura 1: Atrito em cerâmica, ilustrações esquemáticas: a) Tipos de trincas introduzidas por atrito, onde $\mathrm{W}$ é a carga normal no ponto de contato e F a força de atrito na zona de contato [8]; b) superfície desgastada de mancais de alumina sujeitos ao desgaste severo [9]. [Figure 1: Friction in ceramics, schematic illustrations: a) Types of cracks introduced by friction, where $W$ is the normal load at the point of contact and the F friction force in the contact zone [8]; b) worn surface of alumina bearings subject to severe wear [9].]

ponto de contato, o desgaste predominante ocorre através das partículas formadas por propagação de algumas destas trincas [9]. Na Fig. 1b é mostrada esquematicamente a superfície resultante de um mancal de alumina devido ao regime severo de desgaste [9].

Se partículas semelhantes a escamas são supostamente formadas pela propagação de trincas laterais, iniciada na zona plástica na superfície, então o volume desgastado pode ser dado qualitativamente pela equação A e pode ser utilizado para avaliar o desgaste. Esta equação superestima o desgaste, tal que o modelo para a teoria assume propagação de uma trinca lateral na superfície em uma simples passagem de atrito abrasivo [10].

$$
\mathrm{V}=\alpha \frac{\mathrm{W}^{9 / 8}}{\mathrm{~K}_{\mathrm{c}}^{1 / 2} \mathrm{H}^{5 / 8}}\left(\frac{\mathrm{E}}{\mathrm{H}}\right)^{4 / 5} l
$$

na qual $V$ é volume desgastado, $W$ a carga normal, $H$ a dureza, $K_{c}$ a tenacidade, $E$ o módulo elástico, $l$ a distância percorrida e $\alpha$ uma constante independente do material. Pela equação A é possível avaliar qualitativamente a tenacidade à fratura de pares tribológicos semelhantes pela análise da taxa de desgaste.

\section{MATERAIS E MÉTODOS}

O projeto visa o atendimento da necessidade de usuários pesquisadores ou técnicos, seja para estudos de ciência e pesquisa como para fins industriais de desenvolvimento ou controle de qualidade. Os materiais cerâmicos têm sido amplamente usados em aplicações onde a resistência ao desgaste e a dureza são fundamentais. Iniciativas de padronização do equipamento pin-on-disc foram muito discutidas nas décadas de 80 e 90 [11,12] culminando na elaboração da norma ASTM G99, publicada em 1999. Aspectos conceituais do equipamento permitem uma liberdade no desenvolvimento do produto, sendo estes relacionados com a capacidade do usuário obter corpos de prova nas condições que o fabricante estipulou.

Usuários de equipamentos pin-on-disc apontam como 
maior dificuldade a fabricação de discos do par tribológico. $\mathrm{O}$ furo nos disco para fixação, comum à maioria dos equipamentos, é sempre um complicador para diversos laboratórios. Outros equipamentos trabalham com disco, mas com furo descentralizado para arraste, que também traz dificuldade na manufatura. $\mathrm{O}$ desejo dos usuários esta em poder se utilizar peças diversas como discos com e sem furos (bolachas), placas, pastilhas e também que possam ser utilizadas várias trilhas de contato ajustáveis para aplicação em peças com variadas dimensões, ou até mesmo para minimizar a necessidade de retificação dos discos pelo uso de várias trilhas em um mesmo disco.

\section{Conceito}

A realização de ensaios de desgaste do tipo pin-on-disc é regida pela norma ASTM G99-05, Standard Test Method for Wear Testing with a Pin-on-Disk Apparatus. As premissas para o presente projeto são: a possibilidade do emprego de discos, placas ou pastilhas que requer conceito da fixação do suporte de disco pela parte inferior do eixo de rotação do disco; medições de força de atrito ao longo do ensaio; instalação de um sistema de aquisição de dados; tamanho do equipamento compacto e de bancada; controle e manutenção da velocidade angular durante o ensaio com a aplicação de torque adequado; criação de um canal para retenção da fuga do fluído lubrificante; calibragem da carga no sistema montado e pronto para o ensaio e capacidade de amortecimento de vibrações.

\section{Projeto Preliminar}

A Fig. 2 ilustra o projeto em ambiente CAD, mostrando em 2(a) o equipamento montado e em 2(b) uma ilustração em corte em desvio apresentando o cálice, suporte do braço e sistema motor. A mesa em granito sintético simplifica a fabricação com o uso de insertos e apresenta um desempenho ao amortecimento interno muito superior aos metais incluindo o ferro fundido [13]. É destacado que a extração do disco é

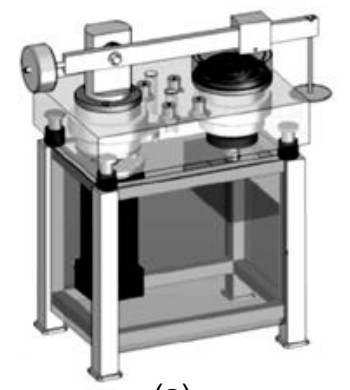

(a) (b)

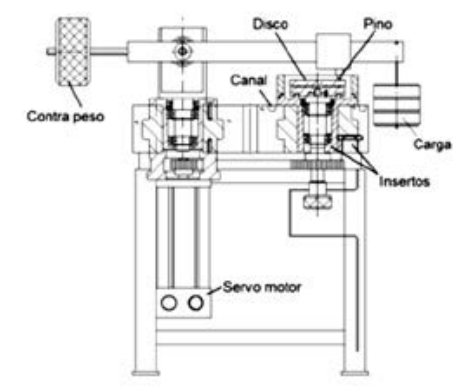

Figura 2: Protótipo virtual do equipamento criado em Solid Edge, com todas as peças, inclusive motor e polias: a) Ilustração do equipamento montado e b) Ilustração em corte.

[Figure 2: Virtual prototype of the machine created in Solid Edge, with all parts, including engine and pulleys: a) Illustration of the equipment and b) Sectional illustration.] feita pelo lado inferior do eixo; o motor é fixado na própria mesa; e existe a liberdade pelo uso de mancais de rolamentos para o giro do braço pelos planos x-y e x-z que permite a medição da força de atrito (plano $x-y)$ e carregamento com contra peso para ajuste fino (plano $\mathrm{x}-\mathrm{z}$ ).

\section{Ensaio de validação}

O ensaio de validação do equipamento foi realizado para verificação e ajustes no projeto.

Preparação do disco e pino. O disco foi produzido pela Saint Gobain, em alumina 99,8\% , teve sua superfície usinada em retífica plana com rebolo diamantado e, em seguida, foi lapidado por $5 \mathrm{~min}$ com carga de $5 \mathrm{~N}$ sobre mesa de ferro fundido com pó de $\mathrm{SiC} \# 500$ mesh e foi aderido sobre o suporte do disco com termocera. Foi obtido Ra médio de 0,81 $\mu \mathrm{m} \pm 0,08$. O pino com cabeça esférica foi produzido com alumina AKP-53, produzida pela Sumitomo, foi conformado uniaxiamente a $50 \mathrm{MPa}$ seguido de prensagem isostática a $200 \mathrm{MPa}$ e sinterizado a $1380^{\circ} \mathrm{C} / 2 \mathrm{~h}$. A fixação desse pino no suporte de aço, para colocação na máquina foi realizada com resina epóxi.

Condições de Ensaio, baseadas nas recomendações de Andersson et al. [9], Blomberg et. al. [14] e Perez Unzueta et al. [15], foram estipulados os seguintes requisitos para o equipamento: • pinos com diâmetro de $6 \mathrm{~mm}$, extremidade esférica com raio de $5 \mathrm{~mm}$; disco com diâmetro máximo de $80 \mathrm{~mm}$, e espessura de 1 a $8 \mathrm{~mm}$; • Preparação da amostra através da lavagem em álcool etílico, secagem a $120^{\circ} \mathrm{C}$ por $30 \mathrm{~min}$, acondicionamento em dessecador por pelo menos durante $30 \mathrm{~min}$ antes da pesagem.

$\mathrm{O}$ pino foi fixado rigidamente no equipamento e deslizado a seco por etapas de $500 \mathrm{~m}$ com carga de $30,0 \mathrm{~N}$, velocidade de $0,5 \mathrm{~m} / \mathrm{s}$ em rotações com diâmetro de $60 \mathrm{~mm}$ e $70 \mathrm{~mm}$, pino 01 e pino 02 , respectivamente. Após cada etapa, foi feita a leitura do peso do pino com resolução de $0,01 \mathrm{mg}$.

\section{RESULTADOS E DISCUSSÃO}

\section{Fabricação do protótipo}

A mesa em granito sintético foi moldada em molde

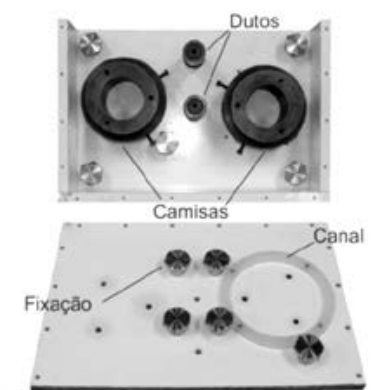

(a)

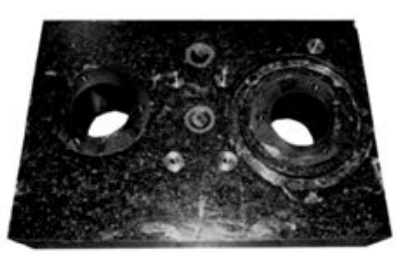

(b)
Figura 3: Mesa, em a) molde aberto mostrando os insertos e em b) mesa bruta.

[Figure 3: Table, in a) open mold showing inserts and b) gross table.] 
de madeira (Fig. 3a) com os insertos. Foram moídas e classificadas britas de granito do tipo cinza Mauá e posteriormente unidas com resina epóxi. Foram selecionados três tamanhos de britas de granito: fino - 0,3 a $1,2 \mathrm{~mm}$; médio - 2 a $4 \mathrm{~mm}$ e grosso - 7 a $12 \mathrm{~mm}$. Foi selecionada experimentalmente uma composição composta por $30 \%$ de grosso, $20 \%$ de médio e $50 \%$ de fino, que resultou na maior densidade de empacotamento de $1,67 \mathrm{~g} / \mathrm{cm}^{3}$. A Fig. $3 \mathrm{~b}$ ilustra a mesa recém moldada.

\section{Estrutura, sistema motor e demais peças}

A estrutura do pin-on-disc foi fabricada em perfil de aço tipo metalon que suportou a mesa em granito sintético, foi dimensionado um sistema de servo-motor WEG SWA562,5-20 e Servo-Conversor WEG SCA050004, com um torque de $2,4 \mathrm{~N} / \mathrm{m}$ através de uma transmissão em correia sincronizadora. Foram empregadas duas células de carga produzida pela MK Controle e Instrumentação Ltda (para aferir o carregamento CSA/ZL-5 e para medição da força de atrito CSA/ZL-10, com capacidade de $50 \mathrm{~N}$ e $100 \mathrm{~N}$, respectivamente, e resolução $0,1 \mathrm{~N}$ ). A Fig. 4a ilustra o protótipo montado e a Fig. $4 \mathrm{~b}$ detalhe mostrando as células de carga. As células com ajuste de posicionamento para a linha de atuação das cargas. O porta-amostra pode ser ajustado no braço em até sete posições correspondendo os diâmetros de deslizamento sobre o disco de 70, 60, 50, 40, 30,20 e $10 \mathrm{~mm}$.

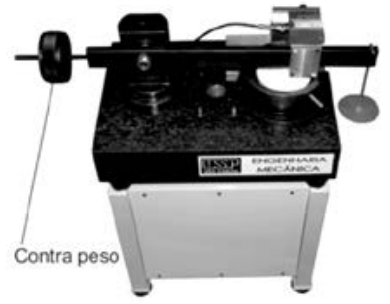

(a)

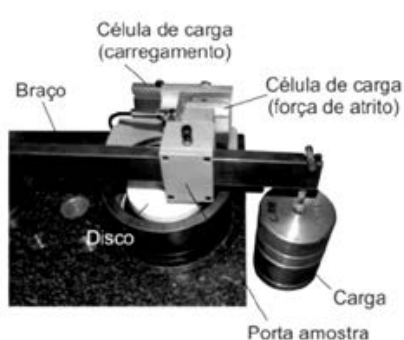

(b)
Figura 4: Protótipo montado, em a) o protótipo em fase final e em b) detalhe das células de carga.

[Figure 4: Prototype mounted in a) the prototype in the final phase and b) detail of the load cells.]

\section{Automação do equipamento}

O controle do equipamento e a aquisição de dados foram feitos empregando o sistema LabVIEW Instrument software e módulo de aquisição de dados NI USB 6009, ambos da National Instruments. O fluxograma de funcionamento e controle está ilustrado pela Fig. 5. A interface gráfica (painel frontal), presente no monitor do computador foi criada no próprio ambiente do software LabView e está ilustrada na Fig. 6. Pela interface gráfica são introduzidos os dados experimentais como: velocidade do ensaio em $\mathrm{m} / \mathrm{s}$; numero da trilha e distância a ser percorrida em metros, o software calcula a velocidade do motor que é apresentada no painel frontal, então ela deve ser digitada ou ajustada no scrollbar, no painel frontal, pelo operador. Após início da operação, é possível acompanhar o ensaio continuamente pela tela do monitor do computador (painel frontal) onde é mostrada a força de atrito variando com o tempo de ensaio e a distância percorrida. Após concluída distância percorrida, o software desliga o servo motor e encerra a aquisição de dados. Na Fig. 7 é apresentado o diagrama de blocos (fluxo de dados entre os ícones) aplicado ao banco, nele são apresentados caixas com textos comentados sobre cada operação realizada pelos ícones.

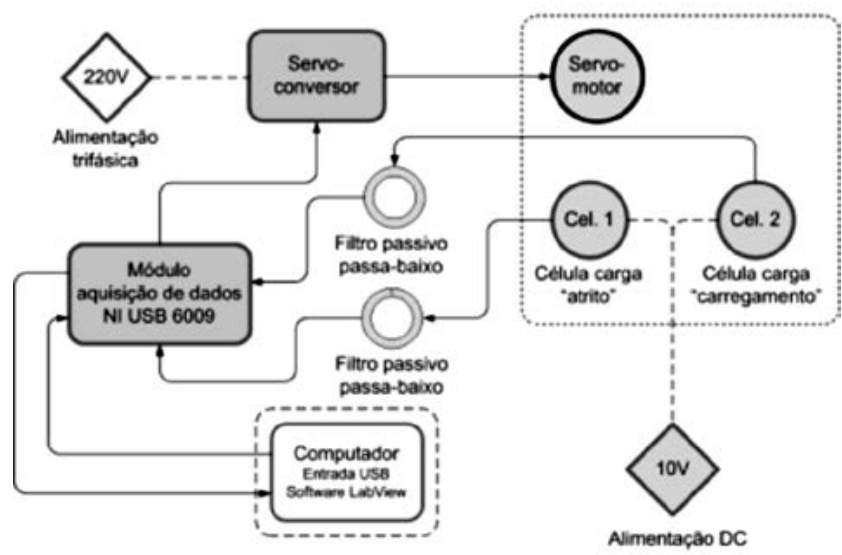

Figura 5: Fluxograma de funcionamento e controle. [Figure 5: Flowchart of operation and control.]

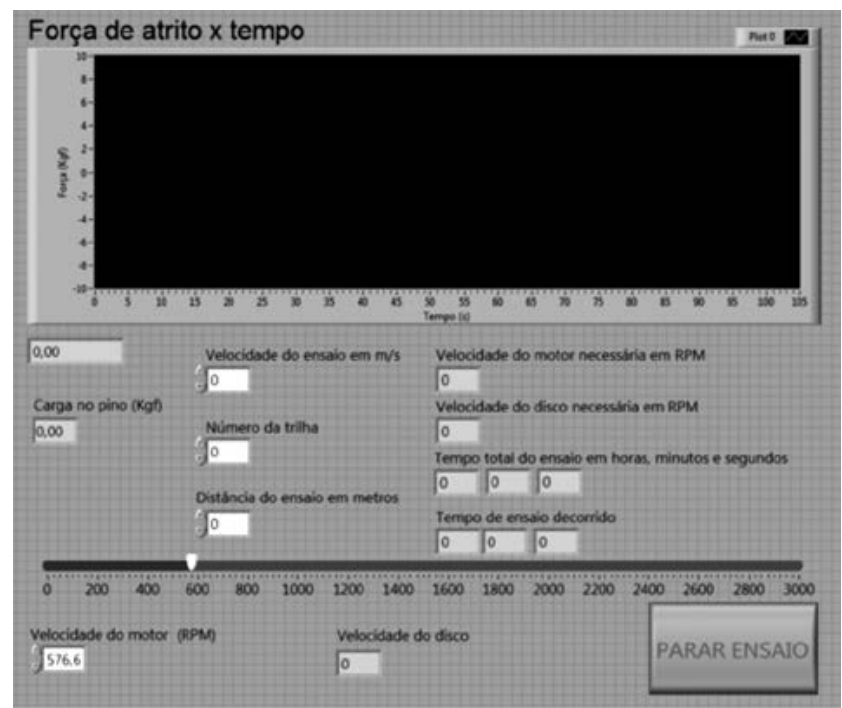

Figura 6: Interface gráfica (painel frontal).

[Figure 6: Graphic interface (front panel).]

\section{Validação}

O equipamento reproduziu os experimentos realizados onde manteve a rotação durante todo ensaio, mostrando que o torque do motor foi suficiente. Através da medição das forças de atrito durante os ensaios e considerando a transmissão com redução de rotação de 2:1 e rendimento 


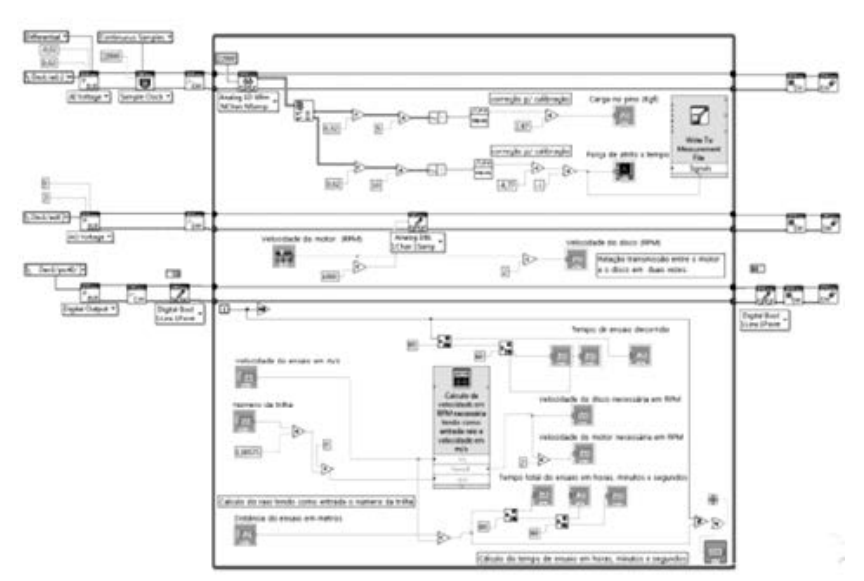

Figura 7: Diagrama de bloco com janelas comentadas sobre ação dos ícones e fluxo de dados.

[Figure 7: Block diagram with commented windows related action icons and data flow.]

para correia sincronizadora de $95 \%$, o experimento consumiu 1,1 N.m sendo que o equipamento oferece 4,56 N.m, tendo considerável reserva de torque para experimentações com maiores solicitações. Foi medida a temperatura na ponta do
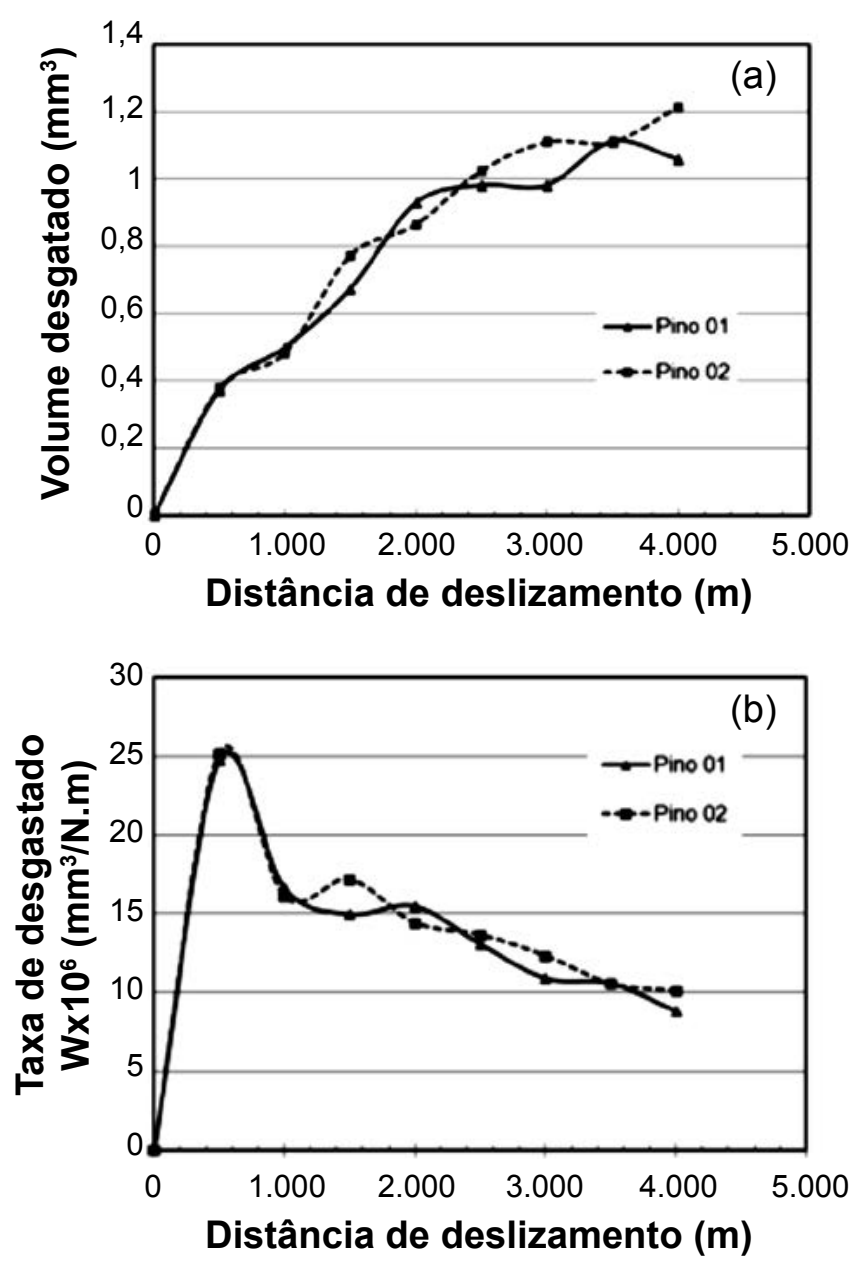

Figura 8: Ensaio de desgaste de pinos de alumina/zircônia, em a) medidas de volume desgastado e em b) taxa de desgaste.

[Figure 8: Test of wear of the alumina/zirconia pins, in a) worn volume measures and b) wear rate.]
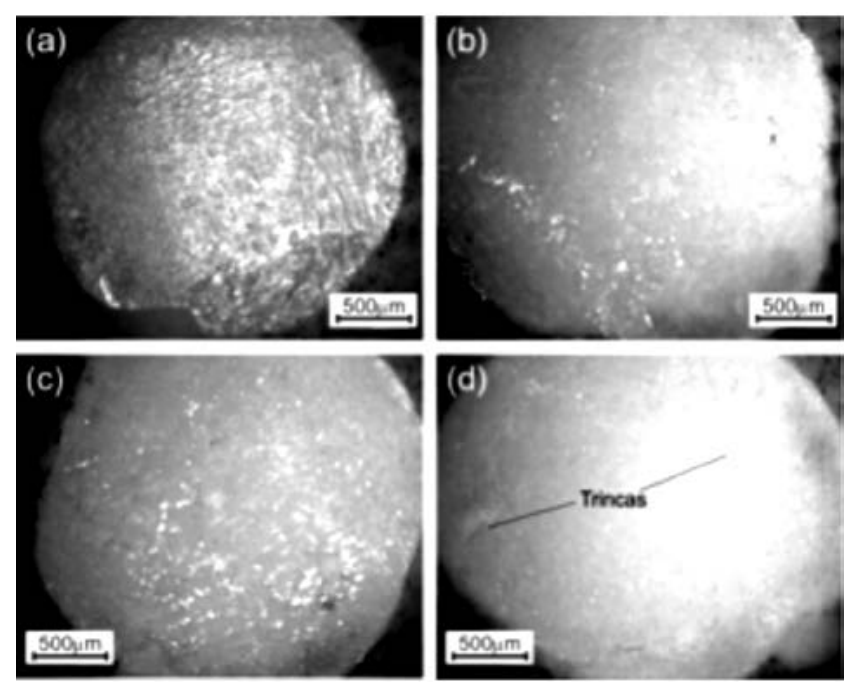

Figura 9: Ilustração das superfícies desgastadas do pino em função do deslizamento, em a) $1000 \mathrm{~m}$, em b) $2000 \mathrm{~m}$, em c) $3000 \mathrm{~m} \mathrm{e} \mathrm{em}$ d) $4000 \mathrm{~m}$.

[Figure 9: Illustration of worn surfaces of the pin versus slip, in a) $1000 \mathrm{~m}$, in b) $2000 \mathrm{~m}$, in c) $3000 \mathrm{~m}$ and in d) $4000 \mathrm{~m}$.]

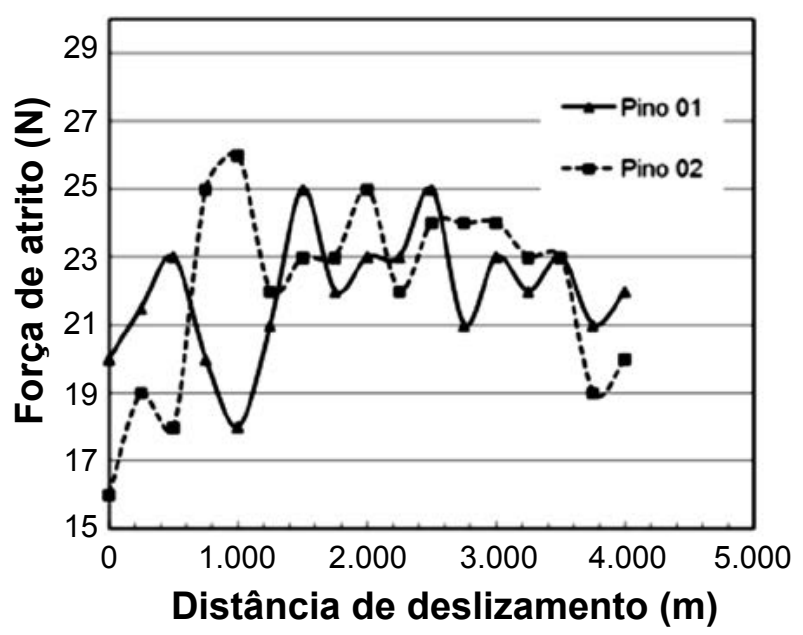

Figura 10: Variação da força de atrito durante o deslizamento. [Figure 10: Variation of friction force during sliding.]

pino que atingiu $90{ }^{\circ} \mathrm{C}$ no período próximo aos $500 \mathrm{~m}$ de deslizamento. É constatado que a fixação do pino cerâmico em suporte metálico quando necessário deve ser feita com adesivo que não libere massa e nem sofra amolecimento nesta faixa de temperatura.

A Fig. 8 mostra as taxas de desgaste obtidas nos primeiros $500 \mathrm{~m}$ de deslizamento, as quais foram de $25 \mathrm{x}$ $10^{-6} \mathrm{~mm}^{3} / \mathrm{N} . \mathrm{m}$, estabilizando próximo a $12 \times 10^{-6} \mathrm{~mm}^{3} / \mathrm{N} . \mathrm{m}$, após $3000 \mathrm{~m}$ de deslizamento, valor considerado dentro da faixa esperada para alumina de alto desempenho. A Fig. 9 ilustra a superfície desgastada do pino durante as fases de deslizamento e a Fig. 10 a variação da força de atrito. Após $3000 \mathrm{~m}$ teve início de trincas na superfície do pino e aumento de massa devido à incorporação de debris. Os valores iniciais da força de atrito foram próximos de $20 \mathrm{~N}$ aumentando no decorrer dos experimentos $(25 \mathrm{~N})$ e retornando para a força 
inicial no final devido ao filme tribológico de debris recompactados na trilha e pino.

Kato [8] relata apanhado de valores para taxa de desgaste de pino de $\mathrm{Al}_{2} \mathrm{O}_{3} 98 \%$, onde se encontram dois valores de comparação: $\mu=0,7$, para velocidade de deslizamento $(\mathrm{v}=0,3 \mathrm{~m} / \mathrm{s})$; carga $\mathrm{P}=9 \mathrm{~N}$; e raio esférico da cabeça do pino, $\mathrm{r}=6,4 \mathrm{~mm} ; \mu=0,3$, para velocidade de deslizamento $(\mathrm{v}=0,4 \mathrm{~m} / \mathrm{s}) ; \operatorname{carga} \mathrm{P}=10 \mathrm{~N}$; e raio esférico da cabeça do pino, $\mathrm{r}=4 \mathrm{~mm}$. O coeficiente de atrito médio encontrado no período de $2000 \mathrm{~m}$ foi $\mu_{2000 \mathrm{~m}}=0,76$; esse valor também é similar ao relatado nas pesquisas. Observaram-se variações acentuadas nestes valores no início do experimento que contrasta com as variações nas imagens superficiais dos pinos, mostrando a sensibilidade do equipamento na leitura indireta deste fenômeno.

\section{CONCLUSÕES}

O protótipo de ensaio de desgaste tipo pin-on-disc projetado e fabricado apresentou excelente desempenho, relativamente às taxas de desgaste realizadas. Apresentou torque suficiente com reserva para manutenção da velocidade nas condições empregadas. Foi constatada certa vibração intrínseca ao atrito justificando a decisão pela escolha da mesa em granito sintético, material este que amortece sobremaneira as vibrações internas do equipamento. A calibração da carga e as medidas de força de atrito validaram a adoção das duas células de carga que facilitou o ensaio e garantiu qualidade e precisão nas condições estabelecidas. O sistema software-drive LabView se mostrou flexível e robusto, capaz de realizar até 48000 aquisições por segundo que permite um excelente espectro de pontos para tratamento dos dados.

\section{AGRADECIMENTOS}

Ao $\mathrm{CNPq}$ pelo financiamento do protótipo e pela concessão de bolsa de Iniciação Científica PIBIC.

\section{REFERÊNCIAS}

[1] Y. Wang, S. M. Hsu, "Wear and wear transition modeling of ceramics", Wear 195 (1996) 35-46.

[2] F. Xiong, R. R. Manory, "The effect of test parameters on alumina wear under low contact stress", Wear 236 (1999) 240-245.

[3] D. P. Mondal, S. Das, A. K. Jha, A. H. Yegneswaran, "Abrasive wear of $\mathrm{Al}$ alloy- $\mathrm{Al}_{2} \mathrm{O}_{3}$ particle composite: a study on the combined effect of load and size of abrasive", Wear Abrasive 223 (1998) 131-138.

[4] B. J. Briscoe, M. J. Adams, "Tribology in particulate technology", IOP Publishing Ltd., ISBN 0-85274-425-0 (1987) 319-334.

[5] J. A. Hawk, R. D. Wilson, J. H. Tylczak, Ö. N. Dogan, "Laboratory abrasive wear tests: investigation of test methods and alloy correlation", Wear abrasive 225-229 (1999) 1031-1042.

[6] D. Amutha Rani, Y. Yoshizawa, H. Hyuga, K. Hirao, Y. Yamauchi, "Tribological behavior of ceramic materials $\left(\mathrm{Si}_{3} \mathrm{~N}_{4}, \mathrm{SiC}\right.$ and $\left.\mathrm{Al}_{2} \mathrm{O}_{3}\right)$ in aqueous medium", J. Eur. Ceram. Soc. 24 (2004) 3279-3284.

[7] A. Ravikiran, "Influence of apparent pressure on wear behavior of self-mated alumina", J. Am. Ceram. Soc. 83, 5 (2000) 1302-1304.

[8] K. Kato, "Tribology of ceramics", Wear 136 (1990) 117 133.

[9] P. Andersson, A. Blomberg, "Alumina in unlubricated sliding point, line and plane contacts", Wear 170 (1993) 191-198.

[10] K. Kato, "Classification of wear mechanisms/models", Proc. Inst. Mech. Eng. 216, Part J: J. Eng. Tribology, Special Issue Paper (2002) 349-355.

[11] K. F. Dufrane, "Wear performance of ceramics in ring/ cylinder applications", J. Am. Ceram. Soc. 72, 4 (1989) 691695.

[12] K. H. Zum Gahr, "Sliding wear of ceramic-ceramic, ceramic-steel and steel-steel pairs in lubricated and unlubricated contact", Wear 133 (1989) 1-22.

[13] P. A. S. Wrege, C. A. Fortulan, B. M. Purquerio, F. M. M. Ribeiro, "Opção eficiente para estruturas de máquinas de precisão", Máquinas e Metais 397 (1999) 60-68.

[14] A. Blomberg, M. Olsson, S. Hogmark, "Wear mechanisms and tribo mapping of $\mathrm{Al}_{2} \mathrm{O}_{3}$ and $\mathrm{SiC}$ in dry sliding", Wear 171 (1994) 77-89.

[15] A. J. Perez-Unzueta, J. H. Beynon, M. G. Gee, "Effects of surrounding atmosphere on the wear of sintered alumina", Wear 146 (1991) 179-196.

(Rec. 06/05/2014, Ac. 28/06/2014) 